\title{
An efficient process for the transformation of betulin to betulinic acid by a strain of Bacillus megaterium
}

\author{
Dhirendra Kumar ${ }^{1} \cdot$ Kashyap Kumar Dubey ${ }^{1,2}$
}

Received: 24 September 2016/ Accepted: 30 January 2017/Published online: 16 June 2017

(C) Springer-Verlag Berlin Heidelberg 2017

\begin{abstract}
Betulinic acid as a derivative of betulin is widely reported for its anti-HIV and antitumor activities. Betulin has three most significant positions, i.e., primary hydroxyl group at position C-28, secondary hydroxyl group at position $\mathrm{C}-3$, and alkene moiety at position $\mathrm{C}-20$, where chemical modifications were performed to yield pharmacologically more active derivatives. Bioconversion optimization was performed for the enhancement in the percentage of conversion using statistical approach by opting temperature, $\mathrm{pH}$ and betulin concentration as independent variables. Three hundred fifty isolates were screened from natural sources under selective medium containing up to $3 \mathrm{~g} / \mathrm{l}$ of betulin for their tolerance and bioconversion efficiency. Isolate $\mathrm{KD} 235$ was found to grow in $3 \mathrm{~g} / \mathrm{l}$ betulin with $23.34 \pm 0.57 \mathrm{~g} / \mathrm{l}$ biomass and $0.67 \pm 0.06 \mathrm{~g} / \mathrm{l}$ betulinic acid production. New isolate KD235 was characterized by molecular analysis and named as Bacillus megaterium KD235. Molecular characterization of a potentially active isolate for the transformation of betulin to betulinic acid was suggested as isolate Bacillus megaterium KD235. Maximum bioconversion $(22 \pm 1.5 \%)$ was found at optimized conditions, i.e., $\mathrm{pH}$ 6.5 , temperature $30^{\circ} \mathrm{C}$ and at $3 \mathrm{~g} / \mathrm{l}$ betulin. Validations of experiments as $\sim 11 \%$ more bioconversion i.e., $1 \pm 0.1 \mathrm{~g} / \mathrm{l}$ betulinic acid were obtained using 51 lab fermenter as compared to shake flask.
\end{abstract}

Kashyap Kumar Dubey

kashyapdubey@gmail.com; kashyapdubey@cuh.ac.in

1 Microbial Biotechnology Laboratory, University Institute of Engineering and Technology, Maharshi Dayanand University Rohtak, Rohtak, Haryana 124001, India

2 Department of Biotechnology, Central University of Haryana, Jant-Pali, Mahendergarh, Haryana 123031, India
Keywords Bacillus megaterium · Betulin ·

Biotransformation · Pharmacological properties · HPLC . Betulinic acid

\section{Introduction}

In the recent past 20 years, betulin (Fig. 1) and its derivatives as penta-cyclic triterpenes have attracted attention due to their diverse pharmacological activities. among which anti-HIV and anti-tumor activities are of prime concern (Aiken and Chen 2005; Alakurtti et al. 2006; Saxena et al. 2006; Csuk 2014). The bioactive molecules' utilization from natural products offered exciting possibilities for the development of successful therapies. Terpenoids are group of phytochemical made up of squalene or related cyclic and acyclic 30-carbon precursors with already reported diverse biological activities (Domingues et al. 2014). Recent findings suggested that betulinic acid improves antioxidant system and reduces lipid peroxidation in the liver (Silva et al. 2016). This improved antioxidant system leads to hepato-protective effects of betulinic acid on alcohol-induced liver damage (Gonzalez-Burgos and Gomez-Serranillos 2012; Yi et al. 2014). Betulin is reported to show anti-fungal and anti-tumor activities as well (Alakurtti et al. 2006). A research group showed significant antifungal activities demonstrated by two Candida species, Candida krusei and Candida albican (Yogeeswari and Sriram 2005). Betulinic acid as a derivative of betulin has already been reported for its multiple pharmaceutical activities. Betulinic acid itself and with its derivatives has been considered for their specific cytotoxicity against various tumor cell lines and anti-HIV activity. Structurally betulin has three most significant positions where chemical modifications can be easily performed, namely primary 


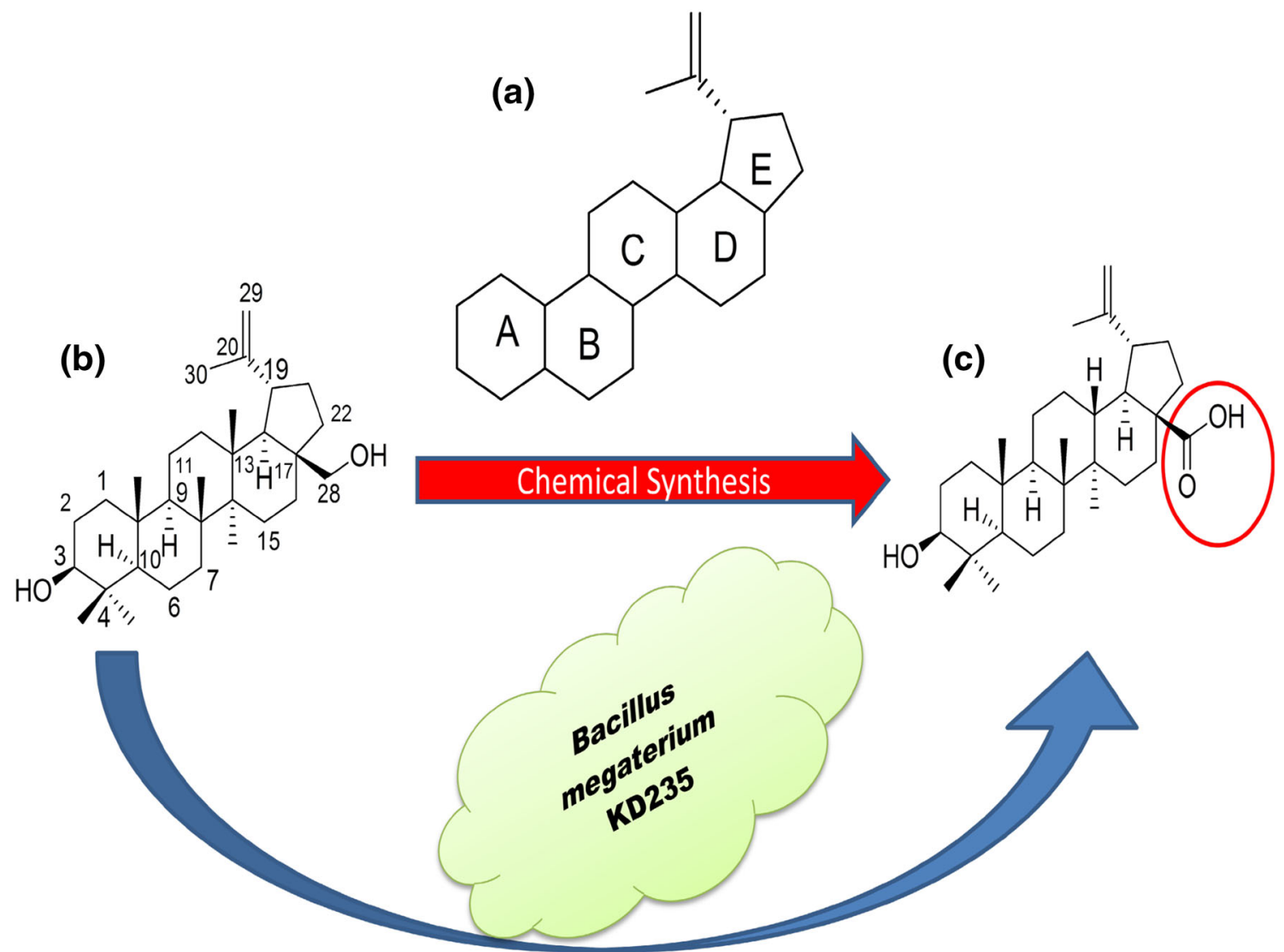

Fig. 1 a Lupane type pentacyclic skeleton representing marked rings. b Structure of betulin representing different functional groups with position of carbon. c Betulin is biotransformed into betulinic acid

hydroxyl group at position C-28, secondary hydroxyl group at position $\mathrm{C}-3$, and alkene moiety at position $\mathrm{C}-20$, as shown in (Fig. 1b). Earlier studies on chemo-synthetic pathway of betulinic acid mainly focus on the oxidation and reduction at position C-28 of betulin (Csuk et al. 2006). However, there are not enough literatures available on microbial transformations of betulin. Reports suggest that betulin can be transformed 3-5 metabolites (Chatterjee et al. 2000; Feng et al. 2013). The bio-chemical modifications at positions C-28 of the parent structure of betulin can produce betulinic acid (Fig. 1b) (Yogeeswari and Sriram 2005; Csuk et al. 2006; Baratto et al. 2013; Bache et al. 2014; Csuk 2014). Betulinic acid is commercially produced via chemical synthesis where betulin is used as raw material (Csuk et al. 2006). Biotransformation is preferred as an alternative route for chemical synthesis because biotransformation does not include large amount of costlier chemicals and leads to green synthesis of high-value fine chemicals (Schwab et al. 2013). Besides that, biotransformation methods are more stereo- and regio-selective. Including that few reactions that cannot be easily completed thorough chemical approaches are performed by microbial transformation in an easier way (Pervaiz et al. by Bacillus megaterium KD235 and the modification is highlighted by red color circle (Fig. 1c)

2013; Bastos et al. 2007; Liu et al. 2011; Mao et al. 2012; Feng et al. 2013; Chen et al. 2008; Shao et al. 2016). Cunninghamella blakesleeana has also been investigated for biotransformation of betulin to betulinic acid analyzed by HPLC (Feng et al. 2013). The LC-MS characterization of this Cunninghamella blakesleeana catalyzed broth extract demonstrated five products among which betulinic acid was the most important (Feng et al. 2013). While in another report, under optimum conditions Rhodotorula mucilaginosa transformed $52.65 \%$ betulin to two products out of which one was detected as betulone (Mao et al. 2012). Another group of researchers investigated betulin transformation to betulinic acid using Armillaria luteovirens Sacc-QH with $\sim 9.32 \%$ maximum productivity of betulinic acid under optimized environment (Liu et al. 2011). The growing cells of Rhodococcus rhodochrous IEGM 66 transformed $0.50 \mathrm{~g} / \mathrm{l}$ betulin to betulone with $45 \%$ conversion rate within $240 \mathrm{~h}$ (Grishko et al. 2013). The present work is focused on bioprospection of an efficient biocatalyst for conversion of betulin to betulinic acid. Moreover, an improved bioprocess will also be developed through optimizing process variables for enhancement of bioconversion rate. 


\section{Materials and methods}

\section{Chemicals and reagents}

Standard betulin (98\%) and betulinic acid (90\% technical grade) were purchased from Sigma Aldrich Inc. Bangalore (India) and dissolved in dichloro-methane (also known as methylene di-chloride) $1 \mathrm{mg} / \mathrm{ml}$ as a stock solution for experiments. Acetonitrile, methanol, and milli-Q water (HPLC grade) were obtained from SRL Limited (Mumbai). Other components of media used in the study were of analytical grade, purchased from Hi-media, Merck and SRL Mumbai.

\section{Collection, isolation, and acclimatization of isolated consortium}

The microbial consortiums capable of growing under betulin stress were grown by enrichment culture in $250 \mathrm{ml}$ flask similarly as followed by other researchers (Liu et al. 2011; Mao et al. 2012; Grishko et al. 2013). Initially isolated microbes were exposed for 05 weeks at $1 \mathrm{~g} / \mathrm{l}$ betulin stress and then stable colonies as the resistant isolates were obtained after 6 weeks. These isolates were acclimatized for next generation with higher betulin concentration gradually. The pure cultures of isolates were identified according to "Bergey's Manual of Determinative Bacteriology" (Vos et al. 2011).

\section{Screening of most suitable biocatalyst for betulin biotransformation}

Different isolated cultures from betulin-enriched medium were separately inoculated to $50 \mathrm{ml}$ betulin screening medium (BSM) containing $2.5 \mathrm{~g} / 1$ of dextrose, $0.25 \mathrm{~g} / \mathrm{l}$ yeast extract, $1.25 \mathrm{~g} / \mathrm{l}$ peptone, $1.25 \mathrm{~g} / \mathrm{l} \mathrm{NaCl}, 1.75 \mathrm{~g} / \mathrm{l}$ $\mathrm{K}_{2} \mathrm{HPO}_{4}, 0.50 \mathrm{~g} / \mathrm{l}$ beef extract, and betulin $1.0 \mathrm{~g} / \mathrm{l}$, in $250 \mathrm{ml}$ Erlenmeyer flask, at $37^{\circ} \mathrm{C}, \mathrm{pH} 6.5$ for $48 \mathrm{~h}$. Further $0.1 \mathrm{ml}$ culture broth was inoculated to solid medium and cultivated for next 4-5 days for different isolates. The betulin-tolerant isolates were screened and maintained on modified nutrient agar and LB medium plates for auxiliary tests. Stock cultures of microbes were stored on slants of nutrient agar at $4{ }^{\circ} \mathrm{C}$ in refrigerator. The culture media used contained organic nitrogen sources (peptones, yeast extracts, tryptone, beef extracts, etc.) and carbon source (glucose, maltose, glycerin etc.) at a pH of 4.5-8.5, and the incubation temperature ranged from 25 to $45{ }^{\circ} \mathrm{C}$. The pure cultures were maintained by transferring to fresh slants on every 15 days, whereas only fresh cultures were used for biotransformation experiments (Fig. 2).

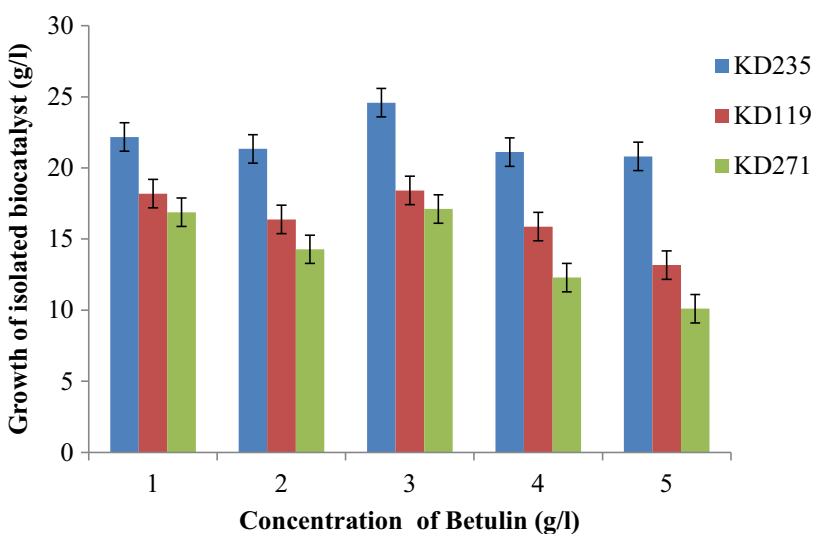

Fig. 2 Comparative growth profile of selected biocatalyst under betulin stress

\section{Morphological and biochemical identification of suitable isolates for betulin biotransformation}

The morphology of different isolates was observed under a camera-attached microscope (Labomed-Luxedo 4D). Various biochemical tests were performed for the identification of betulin-tolerant isolates (Vary 1994). The pure cultures were grown on nutrient agar or potato dextrose medium and transferred to Luria-Broth, Mac-conkey agar medium, EMB agar medium, and Mannitol salt agar medium for differentiating and identifying bacteria. The plates were incubated inverted at $28-37{ }^{\circ} \mathrm{C}$ in the incubator and growth were observed on every $24 \mathrm{~h}$ intervals for 05 days after inoculation.

\section{Molecular characterization}

One of the screened isolates (i.e., KD235) revealed similarity to Bacillus megaterium based on "Bergey's Manual of Determinative Bacteriology" (Vos et al. 2011). Molecular characterization of isolate KD235 was outsourced by Xcelris Labs Limited, Ahmadabad (Gujarat State, India). The 16S rDNA analysis of reference stains with isolate KD235 shown 99\% similarities to Bacillus megaterium. The constructed phylogenetic tree indicated isolate KD235 as Bacillus megaterium and further suggested a name as Bacillus megaterium KD235 during current study.

\section{Validation of biotransformation by parameter testing and statistical optimization}

\section{Shake flask level ( $p H$, temperature and betulin concentration)}

Investigating the effect of $\mathrm{pH}$ on biotransformation in shake flask cultures, different $\mathrm{pH}$ were adjusted (4.5-9.0) using $1.0 \mathrm{M} \mathrm{NaOH}$ or $\mathrm{HCl}$. The temperature changes 
$\left(25-45^{\circ} \mathrm{C}\right)$ were controlled in shaking incubator based on statistical design experiment (Design Expert free trial version 9.0). The biotransformation time was started to examine after $36 \mathrm{~h}$ of the addition of betulin as the substrate. The experiments at shake flask culture level were performed in a 250-ml Erlenmeyer flask containing $50 \mathrm{ml}$ medium after inoculating with the Bacillus megaterium KD235 culture. The $\mathrm{pH}$ and shaking were controlled at 6.5 and 180 , respectively, at $30{ }^{\circ} \mathrm{C}$. After $36 \mathrm{~h}$ of inoculation, $0.15 \mathrm{ml}$ of the already prepared betulin stock solution $(1 \mathrm{mg} / \mathrm{ml})$ was added to each flask and maintained under the same cultivation conditions for additional $120 \mathrm{~h}$. Culture control was run with the inoculation of microorganism, while with the addition of the equal amount of dichloromethane instead of betulin. Consequently microorganism was growing while no substrate biotransformation took place in culture control. While substrate control was run without the inoculum that means betulin was present but betulin tolerant biocatalyst (i.e., Bacillus megaterium KD235) was absent keeping rest of the other culture conditions same with the biotransformation experiment. After 6 days biotransformation runs were stopped by harvesting the broth from shake flasks and a clear permeate obtained by filtering the broth using Whatman No. 1 filter paper.

\section{Purification of biotransformed products by silica gel column chromatography and HPLC}

The entire medium was used for further analysis for the presence of betulin and betulinic acid at the end of each experiment. The fermented broth were extracted for $2 \mathrm{~h}$ with different ratios using ethyl acetate $(1: 1,1: 1.5,1: 2$, $1: 2.5,1: 3,1: 3.5$ and 1:4) and all the organic layers were taken individually, and combined together. Further, the extracted solutions were concentrated in vacuum evaporator at $60{ }^{\circ} \mathrm{C}$ (Hahn Shin, South Korea). The dried samples were further used for identification using thin layer chromatography and HPLC. The concentrated organic layer was subjected to column purification. The column was packed with silica gel and saturated with ethyl acetate before loading the sample. Gradient mobile phase consisting of ethyl acetate and hexane with 7:3 ratios was used for elution of betulinic acid (Chatterjee et al. 2000). The eluent was tested by HPLC at $1.0 \mathrm{ml} / \mathrm{min}$ flow rate and with $210 \mathrm{~nm}$ wavelength at room temperature (Liu et al. 2011; Feng et al. 2013). For getting crystals of betulinic acid, the elute was mixed twice the volume of elute with the mixture of ethyl acetate and methanol $(9: 1)$ and is kept at $4 \pm 1{ }^{\circ} \mathrm{C}$ overnight. This crystallized sample was further analyzed for biophysical characterization of betulinic acid by NMR and ESI-MS (Carpenter et al. 1980; Chatterjee et al. 2000).

\section{Experimental design and statistical analysis}

Three factor temperature, $\mathrm{pH}$ and substrate concentration were selected according to statistical design and available literature for biotransformation of betulin (Dubey et al. 2008; Liu et al. 2011). The interaction effect in among these parameters (temperature $25-35^{\circ} \mathrm{C}, \mathrm{pH}$ 5.25-7.25, and betulin concentration $0.9-6 \mathrm{~g} / \mathrm{l}$ ) and their roles in transformation of betulin were determined by RSM. The model was validated at the predicted levels by running all the experiments in triplicate separately (Myers et al. 2016).

\section{Model verification and time-course experiment at 5 l lab fermenter}

The biotransformation process was performed by a procedure similar to normal transformation experiments using the optimized and non-optimized conditions at a 5-1 lab fermenter. Lab-scale experiments were carried out in 51 fermenter (Biostatplus, Sartorius, Germany) with 31 working volume, where 6-bladed turbine type impeller of diameter $50 \mathrm{~mm}$ and the ring type sparger with 24 holes (size of hole $1.5 \mathrm{~mm}$ ) were used. Bacillus megaterium KD235 (15\% v/v) was inoculated in 31 fermentation medium containing $4.5 \mathrm{~g} / \mathrm{l}$ of dextrose, $0.25 \mathrm{~g} / 1$ yeast extract, $1.25 \mathrm{~g} / 1$ peptone, $1.25 \mathrm{~g} / 1 \mathrm{NaCl}, 1.75 \mathrm{~g} /$ $1 \mathrm{~K}_{2} \mathrm{HPO}_{4}, 0.50 \mathrm{~g} / \mathrm{l}$ beef extract, and betulin $3.0 \mathrm{~g} / \mathrm{l}$, and fermentation initiated at $30{ }^{\circ} \mathrm{C}, \mathrm{pH} 6.5$, and with an agitation speed of $150 \mathrm{rpm}$. At the mid of $\log$ phase, approximately after $36 \mathrm{~h}$ of inoculation; betulin $(3 \mathrm{~g} / \mathrm{l})$ was added to the fermentation medium. When the cell density reaches to $0.9 \pm 1.1$; observations started at a regular time interval of $8 \mathrm{~h}$ (such as 36, 44, 52, 60, 68, 76, 82, 90, up to 144 h). Sample of fermented broth was taken to evaluate the cell mass (Dry Cell Weight as g/l) and residual amount of betulin which corresponds to the yield of betulinic acid. The determination of cell mass was done by making a calibration curve between dry cell weigh and optical density at $600 \mathrm{~nm}$ using spectrophotometer (Lab India, 3000 plus). The dry cell weight was determined by measuring the filtrates of culture broth through a Whatman filter paper $(0.2 \mu \mathrm{m})$ after $8 \mathrm{~h}$ of interval.

\section{Results}

\section{Morphological, biochemical and molecular characterization of KD235 as efficient isolate for betulin biotransformation}

Morphological and biochemical identification of isolate KD235

The characterizations of screened microbes were done on betulin screening medium (BSM) by isolating their pure 
cultures, further analyzed by plotting a graph between growth (Dry Cell Weight g/l) and optical density of culture at $600 \mathrm{~nm}$. Due to these similarities and further sugar utilization these three isolates were grouped as Bacillus megaterium. From these three isolates only one (isolate KD235) showed the highest growth and maximum tolerance at $3 \mathrm{~g} / \mathrm{l}$ concentration of betulin. This isolate, i.e., KD235, was further sent for molecular characterization to Xcelris Labs Limited, Ahmadabad (Gujarat state, India).

\section{Molecular characterization of screened isolate, efficient for betulin transformation}

Based on their morphological and biochemical characterization the isolate was assigned in genus Bacillus. Further, the isolate identification was confirmed by molecular characterization and comparing database with the available reference isolates. The molecular analysis of reference stains and KD235 was found similar to Bacillus megaterium (99\%) consequently a name is suggested to this isolate as Bacillus megaterium KD235 (GenBank KR261097).

\section{Statistical optimization of process variables for enhanced bioconversion}

The microbial growth (Dry Cell Weight g/l) of Bacillus megaterium KD235 during the transformation of betulin was considered as response. The experimental design with three replicates, with different variables at center point, was used to verify the most significant factors affecting the betulin biotransformation (Liu et al. 2011; Feng et al. 2013). The RSM was employed to temperature, $\mathrm{pH}$, and betulin concentration (as substrate) and dry cell weight (Dry Cell Weight $\mathrm{g} / \mathrm{l}$ ) for biomass of Bacillus megaterium KD235 as the response was analyzed on bioconversion. In order to fit the empirical second-order polynomial model, central composite designs (CCD) with three factors, at five coded levels, were performed. The biocatalyst was cultivated in shake flasks in above said culture medium with different combinations of parameters set by Design Expert (Trial Version 9.0). The maximum bioconversion (22 $\pm 1.5 \%$ as $0.67 \pm 0.16 \mathrm{~g} / 1$ betulinic acid) with biomass $(23.34 \pm 1.5 \mathrm{~g} / 1$ Dry Cell Weight $\mathrm{g} / \mathrm{l})$ was obtained at $\mathrm{pH} 6.5$, optimal temperature $30{ }^{\circ} \mathrm{C}$, and substrate concentration at $3 \mathrm{~g} / \mathrm{l}$ using shake flask method. Later on, results were transformed to $51 \mathrm{lab}$-scale fermenter which showed better results in $84-90 \mathrm{~h}(1 \pm 0.12 \mathrm{~g} / \mathrm{l}$ betulinic acid and 28.14 g/l Dry Cell Weight (g/l).

\section{Biophysical characterization of betulinic acid, as product of Bacillus megaterium KD235 catalyzed betulin bioconversion}

Three hundred fifty isolates were grown on the BSM (Betulin Screening Media), and among them KD235 showed notable growth in the presence of betulin with high rate of bioconversion to betulinic acid. The data obtained after HPLC analysis was confirmed the presence of betulin and betulinic acid into fermented broth compared with chromatogram of standard chemicals (betulin and betulinic acid) and the retention time was reported as $3.4 \mathrm{~min}$ (Fig. 3a inset picture) and $12.8 \mathrm{~min}$ (Fig. 3b inset picture) for betulin and betulinic acid respectively. The biophysical characterization and structural elucidation of biotransformed products were confirmed by ${ }^{13} \mathrm{C}$ NMR and spectra were recorded at $400 \mathrm{MHz}$ on a Bruker Avance II 400 in DMSO (Table 1). Analysis of the spectra obtained by NMR spectroscopy was carried out to verify the Bacillus megaterium KD235 catalyzed transformed product of betulin (i.e., betulinic acid) and itself to identify the bonds between them. The shift was probably caused by the enzymes secreted by Bacillus megaterium KD235 in the medium creating the new carboxylic group $(-\mathrm{COO})$ at C-28, which replaced alcohol group of betulin. ESI-MS was also done to verify the results which were similar to the available references. The differences shown in the NMR and ESI-MS peaks represent the biotransformation, respectively. Including HPLC analysis, the ESI-MS spectrum of exhibited a molecular peak at $\mathrm{m} / z[\mathrm{M}+\mathrm{H}]^{+} 443.3$ which is representing betulin as the reference compound, while spectrum exhibited a molecular peak at $\mathrm{m} / \mathrm{z}$ $[\mathrm{M}+\mathrm{H}]^{+} 455.2$ indicated betulinic acid as a isolate KD235 catalyzed biotransformed product of betulin used as the sole carbon source.

\section{Effect of temperature and pH on enhancement of biotransformation}

To determine the maximum growth and betulin transformation on suitable temperature for Bacillus megaterium KD235 the experiments were performed at different temperatures ranging from 25 to $45^{\circ} \mathrm{C}$. The maximum microbial growth $22.72 \pm 0.8 \mathrm{~g} / \mathrm{l}$ is evident from Fig. $4 \mathrm{a}$, which is suggested to be directly proportional to betulin biotransformation. Accordingly, maximum betulinic acid production $(32.17 \pm 0.46 \mu \mathrm{g} / \mathrm{l})$ was found at $30{ }^{\circ} \mathrm{C}$ and as the temperature goes on increasing the biotransformation decreases $(7.9 \pm 1.3 \mu \mathrm{g} / \mathrm{l})$ as evidenced by previous findings on biotransformation (Dubey et al. 2008; Grishko et al. 2013). This decrease in biotransformation is because of heat stress and the oxidation of betulin to betulinic acid with reduced enzyme activity of the bacterium (Vary

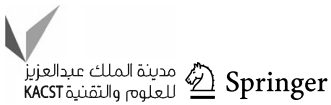


(a)

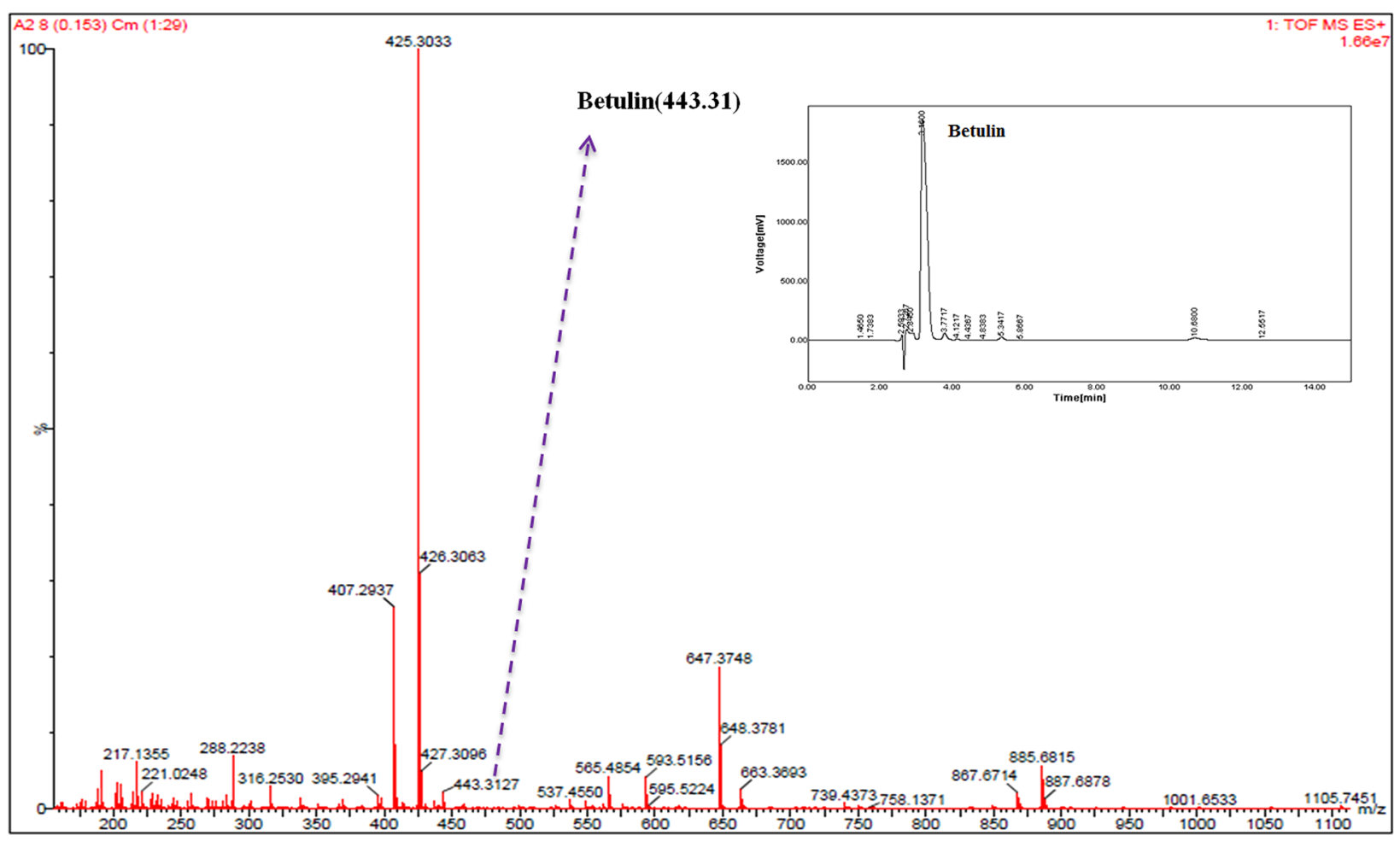

(b)

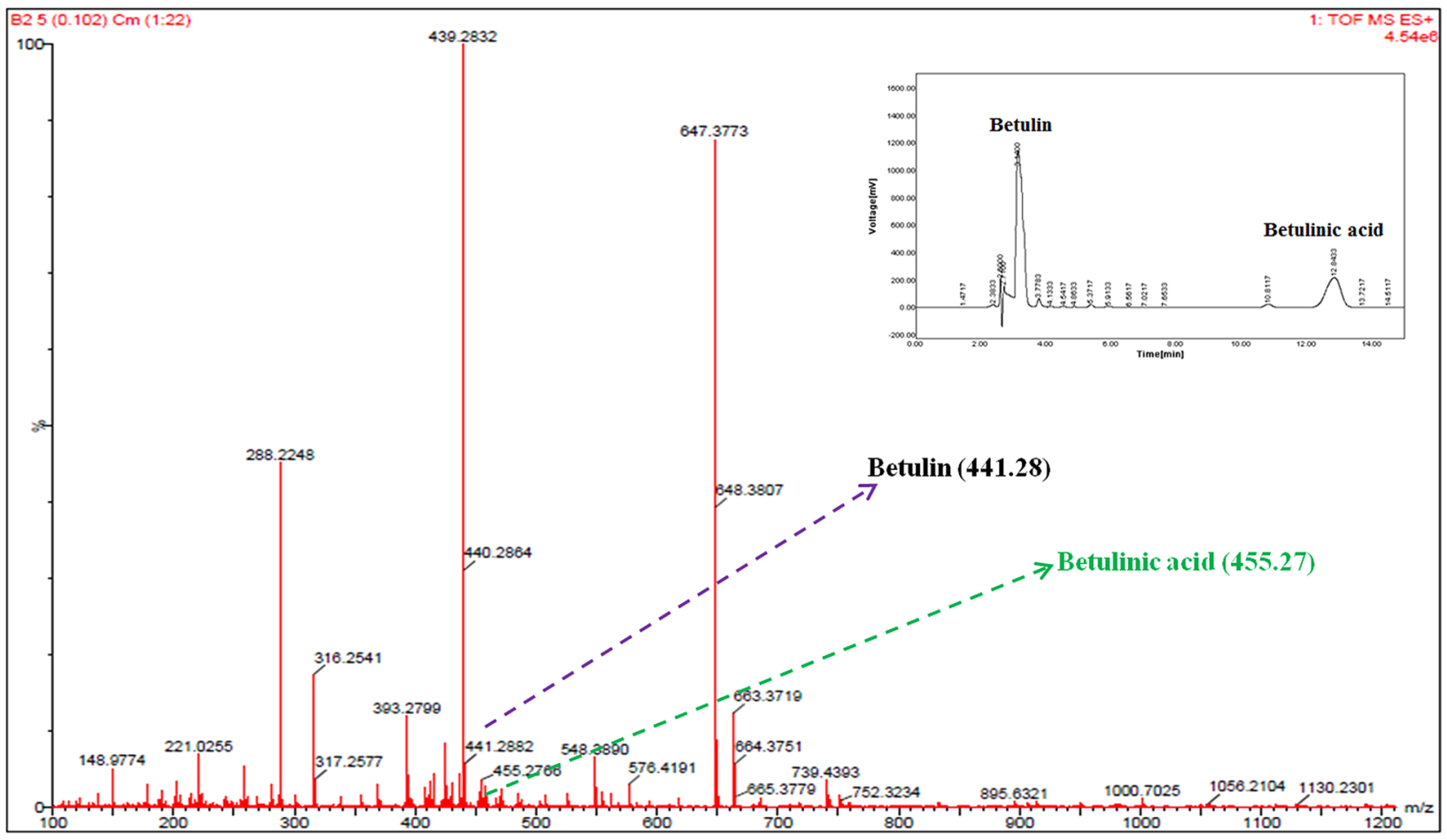

Fig. 3 a Identification (inset image showing HPLC peaks) and characterization of betulin ESI-MS characterization of betulin (443.31 is molecular weight of betulin characterized by ESI-MS). b Identification (showing HPLC peaks in inset image) and characterization of betulin and betulinic acid as products of biotransformation; b ESI-MS characterization of betulin (441.28) and betulinic acid (455.27) characterized by ESI-MS, respectively 
Table $1{ }^{13} \mathrm{C}$ NMR data of betulin and biotransformed product as betulinic acid (400 MHz)

\begin{tabular}{|c|c|c|}
\hline No. of carbon atom & ${ }^{13} \mathrm{C}$ (betulin) & ${ }^{13} \mathrm{C}$ betulinic acid \\
\hline 1 & - & 38.92 \\
\hline 2 & - & 26.35 \\
\hline 3 & 78.98 & 79.05 \\
\hline 4 & 38.94 & - \\
\hline 5 & 54.85 & 55.44 \\
\hline 8 & 40.42 & - \\
\hline 10 & - & 37.61 \\
\hline 11 & - & 20.63 \\
\hline 12 & 25.33 & - \\
\hline 14 & 42.15 & 42.02 \\
\hline 15 & 27.09 & - \\
\hline 16 & 28.97 & - \\
\hline 17 & - & 55.44 \\
\hline 18 & - & 46.50 \\
\hline 19 & - & 49.13 \\
\hline 20 & 150.16 & - \\
\hline 21 & 29.32 & - \\
\hline 22 & 33.80 & - \\
\hline 23 & 27.97 & 26.35 \\
\hline 27 & - & 14.23 \\
\hline 28 & 62.06 & - \\
\hline 29 & 109.37 & - \\
\hline 30 & - & 19.15 \\
\hline
\end{tabular}

1994). To validate the suitable $\mathrm{pH}$ of biotransformation, the experiments were performed according to designed combination of parameters at varying $\mathrm{pH}$ from 4.5 to 8.5 . Due to increase in $\mathrm{pH}$ from 5.25 to 6.5 (Fig. $4 \mathrm{~b}$ ) the rate of biotransformation increases $(16.46 \pm 0.6-33.24 \pm 1.6 \mu \mathrm{g} /$ 1) and gives the maximum growth $(11.32 \pm 1.2-23.34 \pm$ $1.8 \mathrm{~g} / \mathrm{l}$ on $\mathrm{pH}$ 6.5. At $\mathrm{pH}$ higher than 7.5 , reduction in biotransformation was observed $(10.47 \pm 0.8 \mu \mathrm{g} / \mathrm{l})$ and it was assumed that this reduction was due to the production of lesser biomass $(9.87 \pm 1.4 \mathrm{~g} / \mathrm{l})$. It is also demonstrated in Fig. 4b that betulin biotransformation is prone to $\mathrm{pH}$ change towards alkalinity. This decrease in biotransformation is because of stress caused on microbial cells due higher alkalinity (Vary 1994; Grishko et al. 2013).

\section{Effect of betulin concentration on the rate of bioconversion}

To find the effect of the substrate concentrations, experiments were performed in the $250-\mathrm{ml}$ flask with the increasing concentration of betulin ranges from 0.9 to $6.0 \mathrm{~g} / \mathrm{l}$. It is shown in Fig. $4 \mathrm{c}$ that $3 \mathrm{~g} / \mathrm{l}$ conc. of betulin was found to be the most suitable for maximum growth $(22.38 \pm 2.7 \mathrm{~g} / \mathrm{l}$ which is directly proportional to bioconversion of supplied substrate as maximum production of betulinic acid $(32.89 \pm 1.4 \mu \mathrm{g} / \mathrm{l})$. But as soon the betulin concentration rises above $5.0 \mathrm{~g} / \mathrm{l}$ the biomass generation is inhibited $(2.69 \pm 0.3 \mathrm{~g} / \mathrm{l})$ due to toxicity of betulin towards Bacillus megaterium KD235 (Dubey et al. 2008; Grishko et al. 2013). Maximum microbial transformation by Bacillus megaterium KD235 as $0.67 \pm 0.16 \mathrm{~g} / \mathrm{l}$ betulinic acid $(22 \pm 1.5 \%$ bioconversion $)$ and $23.34 \pm 1.2 \mathrm{~g} / 1$ growth were observed. While in case of the whole cell mass of cultured Armillaria luteovirens Sacc ZJUQH100-6 the overall productivity was observed to be only $9.63 \%$ after 3 days of incubation (Liu et al. 2011). In this work betulin tolerant isolate was characterized and named as Bacillus megaterium KD235 (NCBI GenBank reference no. KR261097). It was observed that more than $3.0 \mathrm{~g} / \mathrm{l}$ concentration of betulin hinders the growth of Bacillus megaterium KD235. At $3.0 \mathrm{~g} / \mathrm{l}$ betulin concentration, maximum biomass $\sim 23(\sim 23.34 \pm 1.2 \mathrm{~g} / \mathrm{l})$ and $0.67 \pm 0.16 \mathrm{~g} / \mathrm{l}$ betulinic acid were found using $250 \mathrm{ml}$ shake flask method. These optimized conditions have shown improved results in 5- 1 lab-scale fermenter with the production of $1.01 \pm 0.12 \mathrm{~g} / \mathrm{l}$ betulinic acid and $28.14 \pm 1.7 \mathrm{~g} / \mathrm{l}$ biomass (Table 2). The findings suggested that the production of betulinic acid is directly related to tolerance of betulin to the isolate and its ability to utilize betulin with other available nutrients. With respect to dry cell weight, the productivity of betulinic acid was found to be $0.029 \mathrm{~g} / \mathrm{g}$ in shake flask and $0.036 \mathrm{~g} / \mathrm{g}$ in $51 \mathrm{lab}$ scale fermenter, respectively. Present study indicates that optimized parameters for Bacillus megaterium KD235-catalyzed transformation of betulin into betulinic acid are $3 \mathrm{~g} / \mathrm{l}$ betulin, incubation temperature $30^{\circ} \mathrm{C}$ and $\mathrm{pH}$ 6.5.

\section{Discussion}

Recent reports highlighted that Armillaria luteovirens Sacc ZJUQH100-6 and Cunninghamella blakesleeana may perform the modification (oxidation and reduction) at specific positions of betulin (Liu et al. 2011). Earlier findings for cytochrome P450 ability (CYP450) suggested to perform hydroxylation, oxidation, reduction and demethylation through fungal metabolism (Patten et al. 1993; Nebert and Russell 2002). Mono-oxygenases are the foremost enzymes involved in the microbial metabolism of many of such substrates. Although CYP hydroxylation of cholesterol and testosterone is common in higher eukaryotic systems, the specific CYP monooxygenases that are associated with conversion of steroids are still unknown in microbial system. Thus, it may be assumed that bioconversion of betulin involves the participation of P450, such as monooxygenases and reductase. A previous study reported that action of dehydrogenase can be improved by 
Fig. 4 Representing the effect of (a) temperature $\left({ }^{\circ} \mathrm{C}\right)(\mathbf{b}) \mathrm{pH}$ and (c) Betulin concentration (g/ 1) on betulinic acid production $(\mu \mathrm{g} / \mathrm{l})$ and biomass generation as dry cell weight $(\mathrm{g} / \mathrm{l})$ of Bacillus megaterium KD235
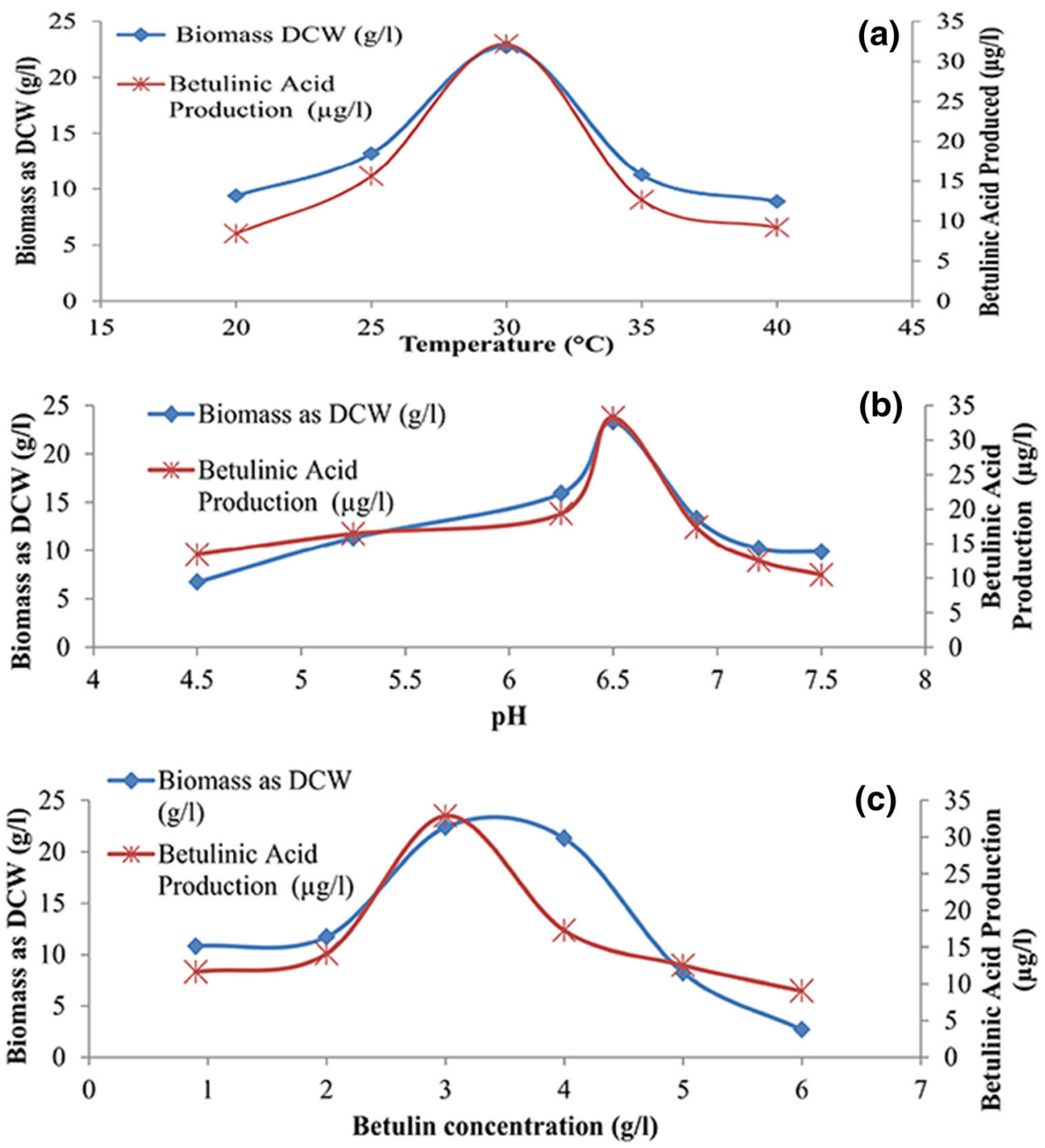

Table 2 Comparative production of betulinic acid by Bacillus megateriumKD235 under optimized conditions

\begin{tabular}{lclll}
\hline Level of culture conditions & Betulinic acid yield $(\mathrm{g} / \mathrm{l})$ & Biomass as DCW $(\mathrm{g} / \mathrm{l})$ & Productivity $(\mathrm{g} / \mathrm{g}$ DCW) & Bioconversion $(\%)$ \\
\hline Shake flask & $0.67 \pm 0.16$ & $23.34 \pm 1.2$ & 0.029 & $22.16 \pm 1.5$ \\
5 1 lab-scale fermenter & $1 \pm 0.12$ & $28.14 \pm 1.7$ & 0.036 & $33.67 \pm 1.1$ \\
\hline
\end{tabular}

increasing the solubility of substrate and product through the addition of a surfactant to the reaction medium. The past reports advocated that betulin and betulinic acid are strongly nonpolar compounds leading to lower hydrophilicity and pose a great problem for pharmaceutical application in vivo. The addition of nonionic hydrophilic surfactant seems to be useful to improve solubility of betulin and overcome mass transfer problem also. Previous study regarding the concentration of precursor highlighted that the concentration of precursor not only affects the biotransformation efficiency but also the procedural cost. When high concentration of betulin was used, the yield of betulinic acid decreased, which may be because of the toxicity of betulin on cells resulting from the high concentration. In a betulin transformation study with Chaetomium longirostre IFO 9873 hydroxylation, oxidative ring cleavage and decarboxylation products were found to be the potent inhibitors of tumor promotion (Akihisa et al. 2002). Another report observed that betulinic acid can be glucosylated and oxidized by the transformation of cultured fungi cells (Bastos et al. 2007). In one study, a nonionic surfactant, span 80 was reported as the best surfactant for enhancing the hydrolysis of castor oil by Candida rugosa. In another study Tween 80 as a surfactant 
considerably improved the biotransformation process of betulin to betulinic acid by Armillaria luteovirens Sacc ZJUQH100-6. The catalytic activity of microbial cells is affected by several factors, such as temperature, cell concentrations, substrate concentrations and $\mathrm{pH}$ values of the buffer solution (Rong et al. 2016). The present study gives a comparative result for the production of biomass at $9.38 \pm 0.4,13.19 \pm 1.1$, and $22.72 \pm 1.3 \mathrm{~g} / \mathrm{l}$ and sharp reduction of biomass to $11.27 \pm 1.4 \mathrm{~g} / \mathrm{l}$ with biocatalytic production of betulinic acid at $8.41 \pm 1.2,15.61 \pm 1.4$, $32.17 \pm 2.6 \mu \mathrm{g} / \mathrm{l}$ and $12.63 \pm 0.6 \mu \mathrm{g} / \mathrm{l}$ with respect to a temperature of $20,25,30$ and $35^{\circ} \mathrm{C}$. The microbial transformation of betulin to betulinic acid is a one-step regioselective oxidation of the primary C-28 hydroxyl group of betulin and is most likely catalyzed by alcohol dehydrogenase. It is well known that $\mathrm{pH}$ plays a crucial role in the dehydrogenase catalyzed reaction. The present study strongly advocates that $\mathrm{pH}$ played a significant role for this feasible bioconversion where production of 13.44 $\pm 1.3,16.46 \pm 1.1,19.38 \pm 0.7$ and $33.24 \pm 2.3 \mu \mathrm{g} / \mathrm{l}$ of betulinic acid was obtained at $\mathrm{pH} 4.5,5.5,6.25$ and 6.5, respectively. On the other hand as the $\mathrm{pH}$ rose to $7 \pm 0.2$ the production of betulinic acid decreased to approximately $15.5 \pm 0.7 \mu \mathrm{g} / \mathrm{l}$. A correlation between cell concentration and conversion rate is typical for many biocatalytic processes. The betulinic acid production was increased with respect to biomass (Dry Cell Weight as g/l) as $11.63 \pm 0.6$, $14.13 \pm 0.5$ and $32.89 \pm 1.8 \mu \mathrm{g} / \mathrm{l}$ of betulinic acid was obtained at $10.82 \pm 0.7,11.73 \pm 0.3$, and $22.38 \pm 1.4 \mathrm{~g} / 1$ biomass, respectively (Fig. 4c). Further cell concentration up to $21.31 \pm 1.7 \mathrm{~g} / \mathrm{l}$ changed this trend, leading to a drastic decrease $(17.28 \pm 0.9 \mu \mathrm{g} / \mathrm{l})$ in betulinic acid production corresponding to betulin biotransformation. This effect may be explained by mass transfer limitations or restrictions of substrate transport caused by the higher cell concentration. Later experiments on higher concentration of substrate have shown that betulin concentrations ranging from 0.9 to $6.0 \mathrm{~g} / \mathrm{l}$ impacted the bacterial respiration where the oxygen uptake reached its maximum within the first $36 \mathrm{~h}$. This period was associated with the highest catalytic activity toward betulin to betulinic acid production (Fig. 4c). A subsequent study found that the respiration rate and the catalytic activity of Bacillus megaterium KD235 decreased and stabilized. Maximal betulin transformation $(32.89 \pm 1.7 \mu \mathrm{g} / \mathrm{l})$ to betulinic acid was achieved after $84 \mathrm{~h}$ at a betulin concentration of $3.0 \mathrm{~g} / \mathrm{l}$. In an earlier study betulone production by Dothideomycete HQ 316564 and Rhodotorula mucilaginosa (Mao et al. 2012) did not exceed 52.65 and $43.4 \%$, respectively, although far lower substrate concentrations were used $(0.57$ and $1 \mathrm{~g} / \mathrm{l}$, respectively).

In an ESI-MS analysis of the transformed product which exhibited the $[\mathrm{M}+\mathrm{H}]^{+}$peaks at $m / z 455.27$ with
$99.83 \%$ relative abundance (Fig. 3 b) the molecular formula of transformed product was determined to be $\mathrm{C}_{30} \mathrm{H}_{48} \mathrm{O}_{3}$. The 13C NMR and 1H NMR data (Table 1) indicated that the acid group ( $-\mathrm{COO})$ is located at the $\mathrm{C}-28$ position. Therefore, the product was identified as betulinic acid (Fig. 1) with the spectroscopic data identical to those reported in the literature (Carpenter et al. 1980). The most reasonable explanation is that the transformation of betulin by Bacillus megaterium KD235 added one oxygen atom in the parent betulin. Microbial transformation strategies are very remarkable for transforming betulin like hydrophobic molecule. Reactive oxygen species (ROS) are highly toxic intermediates generated inside the body as a result of metabolism which promotes aging and different diseases in humans including cancer, neurodegenerative diseases, inflammation, and cardiovascular disease. The present work developed an improved process for getting higher conversion of betulin to their respective derivative, i.e., betulinic acid, which is widely reported to possess significant antioxidant potential using Bacillus megaterium KD235. Betulinic acid is a more potent, relatively nontoxic, more hydrophilic derivative of betulin which has already been reported to possess a wide spectrum of biological activities such as anti-diabetic, anti-cancer, and precursor for anti-HIV drug bevirimat. The present work highlighted a simple, cost-effective process for the biotransformation of betulin to betulinic acid, which is the precursor molecule for synthesis of anti-HIV drugs like DSB, using Bacillus megaterium KD235. Further work on scale up and molecular basis of reaction with enzymatic modulations is needed to be done. The metabolic process is still unknown and the metabolic flux is under further investigation. Indisputably, main enzymes or these reactions involved will need to be investigated in a further study.

\section{Conclusions}

In present study the bioconversion of betulin into betulinic acid was achieved through the structural modification of betulin at carbon 28 position. The bioconversion optimization using statistical approach by opting temperature, $\mathrm{pH}$ and betulin concentration as independent variables was done by isolate KD235. Isolate KD235 was characterized through biochemical as well as molecular analysis and named as Bacillus megaterium KD235. In the present study the isolated strain of Bacillus megaterium KD235 was supplemented with $3 \mathrm{~g} / \mathrm{l}$ betulin which produced $23.34 \pm 1.2 \mathrm{~g} / 1$ biomass and $0.67 \pm 0.16 \mathrm{~g} / 1$ betulinic acid. In these optimized conditions $(\mathrm{pH} 6.5$, temperature $30{ }^{\circ} \mathrm{C}$, and $3 \mathrm{~g} / \mathrm{l}$ betulin) highest bioconversion $(22.16 \pm 1.5 \%)$ of betulin into betulinic acid was obtained. 
Including this, maintenance of culture conditions for Bacillus megaterium KD235 in 5-1 bioreactor caused $\sim 11 \%$ more bioconversion as compared with shake flask (Table 2).

The present work highlighted the process development for the biotransformation of betulin to betulinic acid, which is a precursor molecule for synthesis of novel and more effective anti-HIV drugs using Bacillus megaterium KD235. Further work on scale up and more focus with molecular basis of reaction with enzymatic modulations are needed to be done.

Acknowledgements The authors sincerely acknowledge University Grant Commission, New Delhi, India, for providing the financial support (F. No. 40-119/2011, SR), Maharshi Dayanand University Rohtak, Haryana, India, for providing the necessary lab facilities for this research work. They also wish to thank Xcelris Labs Limited, Ahmadabad (Gujarat state, India), for molecular analysis, AIRF JNU Delhi and SAIF Panjab University, Chandigarh for providing technical support for ESI MS and NMR analysis, respectively.

\section{References}

Aiken C, Chen CH (2005) Betulinic acid derivatives as HIV-1 antivirals. Trends Mol Med 11:31-36

Akihisa T, Takamine Y, Yoshizumi K, Tokuda H, Kimura Y, Ukiya M, Nakahara T, Yokochi T, Ichiishi E, Nishino H (2002) Microbial transformations of two lupane-type triterpenes and anti-tumor-promoting effects of the transformation products. J Nat Prod 65:278-282

Alakurtti S, Mäkelä T, Koskimies S, Yli-Kauhaluoma J (2006) Pharmacological properties of the ubiquitous natural product betulin. Eur J Pharm Sci 29:1-13

Bache M, Bernhardt S, Passin S, Wichmann H, Hein A, Zschornak MP, Kappler M, Taubert H, Paschke R, Vordermark D (2014) Betulinic acid derivatives NVX-207 and B10 for treatment of glioblastoma-an in vitro study of cytotoxicity and radiosensitization. Int J Mol Sci 15:19777-19790

Baratto LC, Porsani MV, Pimentel IC, Netto ABP, Paschke R, Oliveira BH (2013) Preparation of betulinic acid derivatives by chemical and biotransformation methods and determination of cytotoxicity against selected cancer cell lines. Eur J Med Chem 68:121-131

Bastos DZ, Pimentel IC, de Jesus DA, de Oliveira BH (2007) Biotransformation of betulinic and betulonic acids by fungi. Phytochemistry 68:834-839

Carpenter RC, Sotheeswaran S, Sultanbawa MUS, Ternai B (1980) 13C NMR studies of some lupane and taraxerane triterpenes. Org Magn Reson 14:462-465

Chatterjee P, Kouzi SA, Pezzuto JM, Hamann MT (2000) Biotransformation of the antimelanoma agent betulinic acid by Bacillus megaterium ATCC 13368. Appl Environ Microbiol 66:3850-3855

Chen J, Zheng YG, Shen YC (2008) Biotransformation of $p$-methoxyphenyl acetonitrile into $p$-methoxy-phenyl-acetic acid by resting cells of Bacillus subtilis. Biotechnol Appl Biochem 50:147-153

Csuk R (2014) Betulinic acid and its derivatives: a patent review (2008-2013). Expert Opin Ther Pat 24:913-923

Csuk R, Schmuck K, Schäfer R (2006) A practical synthesis of betulinic acid. Tetrahedron Lett 47:8769-8770

Domingues MA, Guerra RR, Duarte A, Freire MSR, Neto CP, Silva CMS, Silvestre JD (2014) Bioactive triterpenic acids: From agroforestry biomass residues to promising therapeutic tools. Mini-Rev Org Chem 11:382-399

Dubey KK, Ray A, Behera B (2008) Production of demethylated colchicine through microbial transformation and scale-up process development. Process Biochem 43:251-257

Feng Y, Li M, Liu J, Xu TY, Fang RS, Chen QH, He GQ (2013) A novel one-step microbial transformation of betulin to betulinic acid catalysed by Cunninghamella blakesleeana. Food Chem 136:73-79

Gonzalez-Burgos E, Gomez-Serranillos MP (2012) Terpene compounds in nature: a review of their potential antioxidant activity. Curr Med Chem 19:5319-5341

Grishko VV, Tarasova EV, Ivshina IB (2013) Biotransformation of betulin to betulone by growing and resting cells of the actinobacterium Rhodococcus rhodochrous IEGM 66. Process Biochem 48:1640-1644

Liu J, Fu M, Chen Q (2011) Biotransformation optimization of betulin into betulinic acid production catalysed by cultured Armillaria luteovirens Sacc ZJUQH100-6 cells. J Appl Microbiol 110:90-97

Mao DB, Feng YQ, Bai YH, Xu CP (2012) Novel biotransformation of betulin to produce betulone by Rhodotorula mucilaginosa. J Taiwan Inst Chem Eng 43:825-829

Myers RH, Montgomery DC, Anderson-Cook CM (2016) Response surface methodology: process and product optimization using designed experiments. Wiley, New York

Nebert DW, Russell DW (2002) Clinical importance of the cytochrome P450. Lancet 360:1155-1162

Patten CJ, Thomas PE, Guy RL, Lee M, Gonzalez FJ, Guengerich FP, Yang CS (1993) Cytochrome P450 enzymes involved in acetaminophen activation by rat and human liver microsomes and their kinetics. Chem Res Toxicol 6:511-518

Pervaiz I, Ahmad S, Madni M, Ahmad H, Khaliq F (2013) Microbial biotransformation: a tool for drug designing. Appl Biochem Microbiol 49:437-450

Rong S, Wang J, Li Q, Guan S, Cai B, Zhang S, Hu J (2016) The enhanced production of $11 \alpha$-hydroxyandrosta-1,4-diene-3,17dione based on the application of organic silica hollow spheres in the biotransformation of $\beta$-sitosterol. J Chem Technol Biotechnol. doi:10.1002/jctb.4983

Saxena BB, Zhu L, Hao M, Kisilis E, Katdare M, Oktem O, Bomshteyn A, Rathnam P (2006) Boc-lysinated-betulonic acid: a potent, anti-prostate cancer agent. Bioorg Med Chem 14:6349-6358

Schwab W, Fuchs C, Huang FC (2013) Transformation of terpenes into fine chemicals. Eur J Lipid Sci Technol 115:3-8

Shao M, Zhang X, Rao Z, Xu M, Yang T, Li H, Xu Z, Yang S (2016) A mutant form of 3-ketosteroid- $\Delta$ 1-dehydrogenase gives altered androst-1,4-diene-3,17-dione/androst-4-ene-3, 17-dione molar ratios in steroid biotransformations by Mycobacterium neoaurum ST-095. J Ind Microbiol Biotechnol 43:691-701

Silva FS, Oliveira PJ, Duarte MF (2016) Oleanolic, ursolic, and betulinic acids as food supplements or pharmaceutical agents for type 2 diabetes: promise or illusion? J Agric Food Chem 64:2991-3008

Vary PS (1994) Prime time for Bacillus megaterium. Microbiology 140:1001-1013

Vos P, Garrity G, Jones D, Krieg NR, Ludwig W, Rainey FA, Schleifer KH, Whitman W (2011) Bergey's manual of systematic bacteriology 3. Springer Science \& Business, Berlin

Yi J, Xia W, Wu J, Yuan L, Wu J, Tu D, Fang J, Tan Z (2014) Betulinic acid prevents alcohol-induced liver damage by improving the antioxidant system in mice. J Vet Sci 15:141-148

Yogeeswari P, Sriram D (2005) Betulinic acid and its derivatives: a review on their biological properties. Curr Med Chem 12:657-666 